\title{
Analysis on Construction and Management Paths for Art Design Laboratory
}

\author{
Daqing Tan \\ School of Arts and Design, Yancheng Institute Of Technology, Yancheng 224051, China
}

\begin{abstract}
Keywords: Art design; Construction and management; Laboratory; Teaching
\end{abstract}
\begin{abstract}
Over many years, the construction and management of laboratory is always an important factor which influences college development, especially for art colleges in which the specialty of art design is established; their experimental courses account for a large proportion in teaching courses, and the experimental teaching is the important content for the students in this specialty to obtain knowledge and improve ability. It can be seen that the construction and management of laboratory is of great importance. Therefore, this paper firstly introduces the features of construction of art design laboratory in colleges and its development, and then analyzes the deficiencies in the construction of art design laboratory, and finally summarizes the effective method to enhance the construction and management of art design laboratory in colleges.
\end{abstract}

\section{Features of construction of art design laboratory in colleges and its development}

In the past, the specialty of graphic design, indoor design, and interior design all belong to industrial art. However, with the development of market economy, those specialties have wider and wider range of application, and there are larger and larger demand for those professional talents in the market; in order to meet this employment demand, the national education department re-divide and re-integrate those specialties as art design. Some colleges take the lead to establish this specialty and recruit students, and then find that the source of students is sufficient, the students have high rate of employment, and this specialty has wide development prospect. After seeing the development prospect of this specialty, many colleges successively establish this specialty and expand investment in equipment introduction, and employ excellent professors and teachers of this specialty for the purpose of improving the faculty and the seizing the source of students. It can seen that the specialty of art design has attracted more and more attention.

At current stage, most of colleges in China are comprehensive colleges; they not only establish the specialties of science and engineering, but also establish the specialties of arts, but the teaching mode is single, and the compulsory courses for many students of different specialties are largely identical with minor differences, and the laboratory applied in the teaching is not separated, which brings great limitation on experimental teaching; in particular, as for students in the specialty of art design, despite of different specialty, the operation content in laboratory is extremely similar, which causes great influence on students. Therefore, the colleges shall pay attention to teaching work for specialty of art design, and carry out teaching based on specialty feature so as to ensure that students' art specialty can be enhanced and their professional ability can be improved.

In recent years, China pays great attention to education work, and the government support is continuously expanded; most of local governments have issued some policies and schemes for laboratory construction, and some local governments even allocate special funds for colleges to purchase laboratory equipments. Currently, the laboratory condition in many domestic colleges has been improved, and students have more chance of hand operation, thus their enthusiasm in attending experimental lesson is improved and their ability of hand operation is enhanced. 


\section{Deficiencies in the construction of art design laboratory in colleges}

\section{No uniform standard for laboratory construction}

At current stage, the colleges have established many types of specialties, most of which are specialties of science and engineering and few of which are specialties of art, thus it is always hard for the colleges to pay equal attention to teaching demand of all subjects in the laboratory construction. Some colleges think that the laboratory is just constructed for students in specialties of science and engineering, and it is unnecessary for students in other specialties to have experimental lessons; some colleges even implement different standard for practice courses of different specialties of science and engineering, let alone pay attention to curriculum standard for specialty of art design. Due to influence of those factors, many difficulties will be met in laboratory construction.

The laboratory is an important teaching place of practice courses, and the knowledge of experimental course is of important teaching significance for students to improve their practical skills. Therefore, the laboratory construction shall meet teaching demand and let the laboratory truly exert its teaching function. Currently, there are three kinds of statements for experimental course of specialty of art design: the first one is that the practice content is the foundation of experimental course, and all contents for which the students need hand operation are experimental course; the second one is that making the material object is the representation of teaching of experimental course; as long as the students make material object, such course is experimental course; the third one is that the laboratory is the only place of experimental course; as long as the students have a lesson in laboratory, such course is experimental course. Among above statements, the first statement has the highest degree of acceptance. The practice courses of all specialties of process design, such as painting, craft, and computer operation all conform to the first statement; despite of different specialties and different proportions of practice courses, all of them have established practice course. Take Dongbei University of Finance \& Economics School of Arts, South China University of Technology School of Arts, Jilin Normal University School of Arts, and Central Luxun Academy of Arts as example: their course arrangement focuses on experimental course; as for some specialties, the experimental courses even account for more than $85 \%$. The experimental course is the course for students in those specialties to carry out key learning and it is of great importance for improving students' practical ability.

\section{Lack of overall planning in laboratory construction}

The art design is a category lately divided by education department with short time of establishment; even for some art academies which have been established for a long time, such specialty is only developed for 20 years; as for most of colleges, such specialty is just established for several years and even established not long ago. Those conditions cause difficulties for laboratory construction. Although most of colleges pay great attention to laboratory construction, it is hard to realize a satisfactory effect due to lack of experience and no clear objective.

Most of colleges face the problem of insufficient fund, thus they have no surplus fund to employ professional laboratory construction talents to carry out planning; instead, the teachers who engage in the teaching work of this specialty guide the design. In this way, the constructed laboratory can only meet this teacher' teaching demand, but hardly meet the experimental teaching demand of other specialties. Besides, in order to obtain government support, some colleges blindly establish special project in laboratory construction, which causes the situation that the laboratory construction is unreasonable and large quantity of experimental equipments introduced are in idle.

The art design is a comprehensive specialty, and it includes many professional subjects and complicated contents, which brings the difficulty for laboratory management. For example, there are many experimental equipments, and the different materials and equipments make it hard for laboratory management personnel to timely carry out checking; some special equipments and devices are very professional, and they need to be managed by management personnel with professional management knowledge. Moreover, there exist similarities and differences in management for many laboratories; if the management personnel can carry out distinctive management, it will be helpful for the laboratory management. Nowadays, in terms of laboratory construction, many colleges borrow 
the ideas from art academies, but neither clearly see the difference between their own laboratory and art laboratory nor consider whether such construction can meet the actual teaching demand of their specialty, which causes many unreasonable problems in laboratory construction. Besides, some colleges seek for the atmosphere of art academies and carry out blind imitation in construction, but ignore their own condition, which causes scattered laboratory construction and hard laboratory construction.

Actually, it is normal that there exist problems in laboratory construction of colleges in which the specialty of art design is established; after all, while we do anything, we shall summarize the experience and make progress step by step. Therefore, the laboratory construction in colleges is a long-term development; as long as we make more efforts and more research and summary, we can avoid detours in laboratory construction and realize better and better construction effect.

\section{Effective methods for enhancing the construction and management of art design laboratory in colleges}

\section{To design laboratory according to features of professional courses}

The art design includes many specialties and belongs to especially complicated comprehensive category; except for a science, it is also a kind of culture and has rich content. The features of this specialty are rich content, multiple subjects, professional, and rapid knowledge updating, which proposes higher requirement for laboratory construction. The laboratory shall be designed according to specialty features so that it can meet the teaching demand of different specialties. Then, I will give a specific introduction to the corresponding arrangement of experimental courses according to three parts of art design curriculum.

The public basic course is a subject which shall be set for most of specialties in colleges; this part of course has basically same content, and all students' public basic experimental course can be conducted in one laboratory activity platform. However, the professional basic course has different experimental content from professional course, thus it is required to set special laboratory to carry out experimental course teaching. For example, as for painting laboratory, upon construction, it is required to pay attention to distribution of indoor space, the students' drawing board and sketching easel occupy great space, and students also require enough space in painting. In case of professional laboratory, it is required to enhance the communication with enterprise upon construction. The laboratory shall be stored with equipments for internship, and there shall be enough space available for students' operation so as to avoid danger. In case of making laboratory, it is required to consult to the teachers of this specialty upon construction, for the laboratory is not only the place for students' learning in practice course, but also the place for teachers' teaching, thus the teaching environment will directly influence teachers' teaching efficiency and teaching quality; in particular, in making specialty, the teachers' instruction plays an important role, thus it is very important that the laboratory is convenient for teachers' teaching. Therefore, the construction of art design laboratory shall take course demand as premise, and the construction shall be made according to the arrangement of experimental course so as to ensure that the laboratory truly conforms to the demand of professional teaching and reflects features of professional teaching.

\section{To carry out reform on laboratory management system}

Due to the fact that the common colleges blindly imitate laboratory management system of art academies in laboratory construction, some problems happen in laboratory management. Therefore, the reform shall be made on management system for art design laboratory so as to ensure that the laboratory can be truly convenient for experimental operation and practice. The specific content is shown as below.

Firstly, the laboratory management can make reference to laboratory management system of art academies, but there shall be some change according to actual teaching demand. Secondly, as for not professional practice course, the teachers of professional courses can manage the laboratory, and reasonably arrange curriculum time according to demand; the teachers can also check and manage the equipments used in experiment, and then deliver them to laboratory management personnel to place 
them into storehouse after completion of course. Thirdly, the laboratory management personnel shall carry out checking on the environment of practice base to avoid any danger in students' practice. Fourthly, while there are many experimental courses and high utilization rate of equipment, the laboratory management personnel shall be careful and responsible, timely check the use condition of laboratory and experimental equipments, and timely repair and change the damaged equipments so as to ensure the utilization rate of laboratory and equipments.

\section{To carry out overall planning on laboratory teaching}

The experimental course is different from theoretical course, and its teaching purpose and teaching means have essential difference with that of theoretical course.

The experimental course has outstanding teaching feature and different teaching purpose; therefore, in order to realize the corresponding experimental teaching effect, it is required to carry out planning work of experimental course, give lessons according to features of experimental course, select suitable experimental projects, arrange reasonable experimental content, and carry out scientific management on experimental course so that the experimental course can exert its teaching function, meet students' learning need, and realize teaching goal.

While we regard the experimental teaching as a whole, we can do well in planning the experimental teaching so as to ensure clear classification and teaching of experimental course for each specialty, ensure that each lesson is independent and consistent, and unify the experimental course to form an organic whole. As for experimental teaching for specialty of art design, it is able to adopt credit system, provide students with the space to select experimental content, and let students take experimental project as an elective course; as long as the students can obtain experimental credit within stipulated time, it can deemed that the students have completed experimental task.

\section{To improve teachers' overall quality and ability}

The teachers are the leader of teaching, and they play an important role in improving students' knowledge ability. Therefore, it is very necessary to cultivate a high-quality teacher team.

The colleges which have established the specialty of art design shall know importance of faculty, and let experimental teachers have more communication with theoretical teachers, and learn from each other so as to improve their ability, which is greatly helpful for improving students' overall practice ability.

In the laboratory construction, the teachers who engage in experimental teaching work shall also propose suggestions to ensure that the laboratory construction is more reasonable, which can help teachers to carry out experimental teaching work and obviously improve experimental teaching efficiency and teaching quality. Besides, the schools shall also pay attention to teacher training, organize teachers to carry out visit investigation and communication, learn the laboratory construction and management methods from other academies, and then combine with the actual situation of their school to carry out rectification and improve laboratory management level.

\section{To carry out joint school running with famous enterprises}

The employment of talents in specialty of art design is the priority among priorities of the school, and how to improve students' employment rate and employment quality is a problem that the school pays key attention. Therefore, in terms of laboratory construction, the school shall have more communication with off-campus talent receiving enterprises, and carry out experimental teaching according to enterprise work demand to let students learn practical knowledge and business ability, which can greatly help students to enter into enterprises in the future. Besides, the school can select large-scale companies to carry out joint school running, which not only can solve the problem of fund shortage of the school, but also can help students' employment in the future.

\section{Conclusion}

The art design laboratory construction is a complicated and difficult task, and it is also a progressive process. As long as the colleges can learn more successful experiences and reasonable suggestions from other schools and combine with their actual teaching demand of each specialty to 
carry out laboratory construction, it is able to guarantee that the laboratory construction can be more perfect and featured so as to be convenient for laboratory staff to carry out management.

\section{References}

[1] Zhang Xinyuan: Practice and Exploration of Utilization of Art Design Laboratory, Laboratory Science, 2009 (02).

[2] Zhang Chunmei: Analysis on Laboratory Construction and Management of Art Subject, China Education of Sports, Sanitation, and Arts, 2010 (11).

[3] Zhang Pengcheng: Exploration on Construction of Art Design Laboratory in Colleges, Collected Papers of 2007 Academic Seminar of Beijing Higher Education Society Laboratory Work Seminar, 2007.

[4] Xu Yi: Exploration and Research on Construction and Management Mode of Art Laboratory, Laboratory Research and Exploration, 2011 (04). 